\title{
BMI open Psychometric properties of a questionnaire to assess exercise-related musculoskeletal injuries in older adults attending a community-based fitness facility
}

\author{
Liza Stathokostas, ${ }^{1}$ Olga Theou, ${ }^{2}$ Tony Vandervoort, ${ }^{3}$ Parminder Raina ${ }^{4}$
}

To cite: Stathokostas $L$, Theou 0, Vandervoort T, et al. Psychometric properties of a questionnaire to assess exercise-related musculoskeletal injuries in older adults attending a community-based fitness facility. BMJ Open 2012;2:e001777. doi:10.1136/bmjopen-2012001777

- Prepublication history and additional material for this paper are available online. To view these files please visit the journal online (http://dx.doi.org/10.1136/ bmjopen-2012-001777).

Received 7 July 2012 Accepted 22 October 2012

This final article is available for use under the terms of the Creative Commons Attribution Non-Commercial 2.0 Licence; see http://bmjopen.bmj.com

For numbered affiliations see end of article.

Correspondence to Dr Liza Stathokostas; Istatho2@uwo.ca

\section{ABSTRACT}

Objectives: There currently exists no reliable or validated tool for the assessment of exercise-related injuries in older adults. The purpose was to develop and evaluate the psychometric properties of a questionnaire to measure exercise-related injury in older adults participating in supervised exercise programmes.

Design: The study utilised a repeated survey design. Setting: The study took place at one communitybased older-adult exercise facility.

Participants: The questionnaire was administered to 110 community-dwelling older adults (45 men, mean age $75 \pm 8$ years; 65 women, mean age $71 \pm 8$ years). All participants completed the survey at both time points.

Outcome measures: Test-retest reliability of the selfadministered written questionnaire was determined at two-time points. The questionnaire asked participants about their exercise-related injury incurred at the facility in the 12 months. Items included the mechanism, cause and site of injury. The minimum requirement for reliability ( $\kappa$ coefficient) was set at 0.80 .

Results: $16 \%(n=18)$ reported having an injury. Test-retest reliability ranged from 0.76 to 1.00 , with all but type of injury (0.76) having $\kappa$ coefficients greater than 0.80 . The lower extremities were the most common site of exercise-related injury. Overexertion movements were the most common cause of injury occurring during strength training exercises.

Conclusions: The present questionnaire assessing the 12-month recall in older adults is a reliable measure of exercise-related injuries and information gained indicates that older adults can safely participate in exercise activities.

\section{INTRODUCTION}

The Centers for Disease Control and Prevention identified injury prevention in sports, recreation and exercise a high-priority area for their Injury Research Agenda (2002-2007) highlighting that little is known

\section{ARTICLE SUMMARY}

Article focus

- The literature does not adequately describe exercise-related injuries in older adults and there is a lack of measurement tools to assess exercise-related injuries in the older adult population.

- The purpose was to evaluate the psychometric properties of a questionnaire to measure exerciserelated injury in older adults participating in supervised exercise programmes.

- A second purpose was to describe the incidence of self-reported exercise-related injuries among the sample of older adults attending a communitybased older adult fitness facility.

Key messages

- Older adults are able to reliably recall exerciserelated injuries.

- It does not appear that older adults are at an increased risk of injury from participation in general multicomponent fitness group classes.

- A greater knowledge of exercise-related injuries could lead to prevention strategies that will assist in the continued and safe participation of older adults in physical activity.

Strengths and limitations of this study

- Strengths of this study include a focused sample of older adults with appropriate documentation of information needed to properly describe exercise-related injuries.

- Limitations of the present study include the relatively small sample size that could provide an incidence rate for injuries that would have resulted in greater power. In addition, the present sample represents an independent older adult population attending supervised exercise sessions.

about the injury risks associated with participation in sports, recreation and exercise in an older adult population (CDC Injury Research Agenda). ${ }^{1}$ Similarly, the Listening 
for Direction on Injury final report ${ }^{2}$ identified the need and potential for collaboration in the areas of sports/recreational injury and the older adult population. Historically, the literature has focused on the types and rates of sports injuries among competitive Masters athletes. ${ }^{3}$ Furthermore, a majority of the literature describes acute traumatic sport-related injuries based on emergency department injury surveillance systems, with variable subcategorisations not conducted for specific age groups. Recently, descriptions of the types and frequencies of injuries focusing on recreationally active adults have emerged; ${ }^{4-6}$ however, very few studies ${ }^{7}$ focus on the older adult age range. Therefore, the literature does not adequately describe exercise-related injuries in the older adults.

Despite the general lack of surveillance in the area of exercise injuries and aging, recommendations for older adults in avoiding injury stress the importance of individualised and/or monitored physical activity programmes, ${ }^{8-10}$ with the need for physical fitness and injury prevention programmes geared towards older adults. ${ }^{9}$ However, the evaluation of strategies for the prevention of exercise-related injuries in older adults is also lacking in the literature. Furthermore, there is a lack of measurements tools to assess exercise-related injuries in the older adult population (and no well-validated tool in younger populations). In order to address this issue, the purpose of this study was to develop and evaluate the psychometric properties of a questionnaire to measure exercise-related injury in older adults participating in supervised exercise programmes. Specifically, to examined the test-retest reliability of the questionnaire and the construct validity of the questionnaire. Our hypothesis for the construct validity component of the study was that self-reported exercise-related injury in the older adult population would be correlated with healthcare provider diagnosis and injury incidence report forms collected at the study site. A second purpose was to describe the incidence of self-reported exercise-related injuries among the sample of older adults attending a community-based older adult fitness facility.

\section{METHODS}

Questionnaire content development

A literature review of exercise-related injury questionnaires generated potential items and questions relevant to the topic. An expert panel was assembled where members consisted of gerokinesiologists, a physical therapist, a sports medicine physician and an epidemiologist in the area of injury research. An expert panel reduced the list of items by a consensus process to a list deemed relevant for assessing exercise-related injuries in older adults and pilot testing of the new questionnaire was conducted. Pilot testing was conducted with 10 individuals, including older adults at the Canadian Centre for Activity and Aging (CCAA), older adults from the general community who do not exercise and individuals from the local academic institution involved in research design. Issues related to the respondents' understanding of the objective of the purpose of the study, the clarity of the wording of the questionnaire and the appropriateness of the responses in relation to the information required were used to modify and finalise the questionnaire. The International Classification of External Causes of Injuries ${ }^{11}$ was used to classify and format questionnaire items for each concept. The questionnaire (see appendix 1, Web Only File) asked participants about their exercise-related injury incurred in the 12 months previous where, injury was defined as a selfreported muscle, tendon, bone, ligament or joint injury. Other items included the mechanism of injury, cause of the injury, anatomical site of the injury, place of injury occurrence and treatment sought.

\section{Setting}

Data collection took place at the CCAA. The CCAA is a research and teaching institute located at the University of Western Ontario, London, Ontario (2011, population 366151 ), offering instructor-led specialised exercise programmes for older adults 55 years of age and older. At the time of testing, there were approximately 200 individuals enrolled at the facility. All exercise classes at the CCAA were developed with the aging participant in mind (including safe participation in exercise) and all instructors (certified by the CCAA) are trained to individualise class components based on the specific medical needs of each participant. Participants can enrol in individual fitness classes that are scheduled two or three times per week. Memberships are available for 10 -month or 12-month durations. The majority of volunteers participated in a 'combined fitness' class which entails $75 \mathrm{~min}$ of group exercise including accelerated walking or other cardiovascular activity, strength training, flexibility and balance training.

\section{Study population}

All participants of the CCAA programmes were offered and eligible to participate. There were no exclusion criteria. Ahead of the scheduled data collection dates, the study was described to CCAA fitness instructors and advertised via posters on the CCAA bulletin boards. The initial data collection date coincided with a monthly social event that takes place after each of the CCAA fitness classes in a common room. On that day, the research coordinator visited each class to recruit participants. The questionnaire was administered to 110 consenting community-dwelling older adults ( 45 men, mean age $75 \pm 8$ y; 65 women, mean age $71 \pm 8$ years) attending the CCAA (table 1). Volunteers participated in an exercise class 2.6 \pm 0.5 days of the week and on average volunteers had been attending the facility for $7.4 \pm 5$ years. All the experimental procedures were approved by The University of Western Ontario Ethics Committee for Research on Human Subjects. 


\section{Table 1 Subject characteristics}

\begin{tabular}{|c|c|c|c|}
\hline & $\begin{array}{l}\text { Total } \\
(n=110)\end{array}$ & $\begin{array}{l}\text { Men } \\
(n=45, \\
41 \%)\end{array}$ & $\begin{array}{l}\text { Women } \\
(\mathrm{n}=65 \text {, } \\
59 \%)\end{array}$ \\
\hline Age (years) & $72.3 \pm 7.8$ & $74.8 \pm 7.5$ & $70.6 \pm 7.5$ \\
\hline $\begin{array}{l}\text { Length of time as a } \\
\text { participant at the exercise } \\
\text { facility (years) }\end{array}$ & $7.4 \pm 4.8$ & $7.3 \pm 4.6$ & $7.4 \pm 5.0$ \\
\hline $\begin{array}{l}\text { Average times per week } \\
\text { exercise class } \\
\text { attended (days) }\end{array}$ & $2.6 \pm 0.5$ & $2.7 \pm 0.5$ & $2.6 \pm 0.5$ \\
\hline $\begin{array}{l}\text { Average number of } \\
\text { months per year exercise } \\
\text { class attended (months) }\end{array}$ & $10.7 \pm 1.0$ & $10.8 \pm 1.0$ & $10.6 \pm 1.3$ \\
\hline
\end{tabular}

\section{Questionnaire test-retest reliability}

Test-retest reliability of the self-administered written questionnaire was determined at two-time points, 1-week apart. Where, 1 week was determined to be of sufficient duration whereby participants were unlikely to recall their previous responses and there was a low risk of additional injury occurrence. The participants were asked to fill out the questionnaire during the first $15 \mathrm{~min}$ of their exercise class on each testing day. The research coordinator and a research assistant were present on both testing days to distribute the questionnaires, provide a working definition of exercise-related injury and to assist with any clarifications in describing an injury or potential injury. The minimum requirement for reliability was set at 0.80 . The $\kappa$-coefficient was used to determine repeatability for categorical variables. In order to validate the data obtained from the questionnaire, participants who reported having an injury were asked to provide contact information for the healthcare provider who treated the injury. For the development of this measurement, a sample size of 100 was based on the approximation of intraclass correlations (with Fisher's z transformation) and using a CI of 0.05 and a reliability coefficient of $0.90 .^{12}$

The sample size for validity assessment included all participating volunteers reporting an injury. A correlation of $>0.4$ was chosen to assess the hypothesis that with respect to the questionnaire, self-reported exercise-related injury was correlated with healthcare provider diagnosis for injuries requiring medical attention or incidence report forms filed by the fitness instructors of the CCAA for injuries not requiring medical attention.

\section{Statistical analysis}

Data analyses were conducted with the first time point data collect and performed with the Statistical Package for the Social Sciences V.19.0 (Ireland, 2010). All descriptive data are presented as mean \pm SD. Frequency distributions were examined for categorical variables. Univariate and stepwise regression analysis was conducted for age, sex, type of exercise class and frequency of attendance per week on injury occurrence.

\section{RESULTS}

\section{Questionnaire test-retest reliability}

All 110 volunteers completed the questionnaire twice. Test-retest reliability of the developed questionnaire ranged from 0.76 to 1.00 , with all but one variable (type of injury, 0.76) having $\kappa$-coefficients greater than 0.80 (table 2).

\section{Questionnaire validity}

The response rate from healthcare providers to validate injuries requiring medical attention was zero. However, for three injuries (of 18) we were able to examine the incidence report forms that are required to be filed by the fitness instructor if the injury occurred and required attention during the fitness class. For these three injuries, the description of injury in the incident report form was comparable to the information provided by the participant in their questionnaire responses.

\section{Incidence of self-reported exercise-related injuries}

Of the 110 volunteers, $16 \% \quad(n=18)$ reported having an injury in the 12-months previous (table 3). The lower extremities were the most common site of exercise-related injury (figure 1). Overexertion or strenuous movements was the most common cause of injury (figure 2) resulting most in an acute muscle strain (figure 3). Injury was most often incurred during strength training exercises (figure 4).

Univariable association indicated only sex as a significant predictor of injury and was the only variable to enter the stepwise multivariable model. If all four variables were forced into the model, sex was the only significant variable $(\mathrm{p}=0.013, \mathrm{OR}=4.22,95 \% \mathrm{CI} 1.36$ to 13.13).

\begin{tabular}{|c|c|c|}
\hline Questionnaire item & $\mathbf{N}$ & $\begin{array}{l}\text { к } \\
\text { Value }\end{array}$ \\
\hline Injury in the past 12 months & 110 & 1.00 \\
\hline Multiple injuries in the past 12 months & 110 & 0.80 \\
\hline Number of injuries in the past 12 months & 2 & 1.00 \\
\hline Part of body injured & 18 & 1.00 \\
\hline Type of injury & 18 & 0.76 \\
\hline Cause of injury & 18 & 0.80 \\
\hline Type of exercise & 18 & 0.86 \\
\hline Location of injury occurrence & 18 & 0.88 \\
\hline Injuries requiring medical Care & 18 & 1.0 \\
\hline Type of medical care & 10 & 1.00 \\
\hline $\begin{array}{l}\text { Injury serious enough to limit normal } \\
\text { activities }\end{array}$ & 18 & 0.89 \\
\hline $\begin{array}{l}\text { Ability to continue participation in exercise } \\
\text { class }\end{array}$ & 18 & 1.00 \\
\hline
\end{tabular}




\begin{tabular}{|c|c|c|c|}
\hline & Total $(n=110)$ & Men $(n=45)$ & Women $(n=65)$ \\
\hline Injury in the past 12 months & $18(16.4 \%)$ & 12 & 6 \\
\hline Multiple injuries in the past 12 months & $2(1.8 \%)$ & 1 & 1 \\
\hline \multicolumn{4}{|l|}{ Location of injury occurrence } \\
\hline Gymnasium & $11(61.1 \%)$ & 6 & 5 \\
\hline Weight room & 7 (38.9\%) & 6 & 1 \\
\hline Injuries requiring medical care & $10(55.6 \%)$ & 7 & 3 \\
\hline Hospital emergency room & $1(10 \%)$ & 1 & - \\
\hline Family/private physician & $7(70 \%)$ & 4 & 3 \\
\hline Other & $2(20 \%)$ & 2 & - \\
\hline \multicolumn{4}{|l|}{ Injury serious enough to limit normal activities } \\
\hline Yes & $7(38.9 \%)$ & 4 & 3 \\
\hline No & $11(61.1 \%)$ & 8 & 3 \\
\hline \multicolumn{4}{|l|}{ Ability to continue participation in exercise class } \\
\hline Yes & $8(44.4 \%)$ & 6 & 2 \\
\hline No & $10(55.6 \%)$ & 4 & 4 \\
\hline Days missed attending exercise class due to injury (days, $n=8$ ) & $52 \pm 90$ & $66 \pm 102$ & $11 \pm 5.0$ \\
\hline
\end{tabular}

\section{DISCUSSION}

Obtaining a general sense of injury rates in the general population is problematic due to the wide range of populations studied (recreationally active to highly competitive), reports of injuries from emergency rooms or sports medicines clinics. Similarly, describing the injuries incurred is difficult due to varying data collection methods and a lack of a commonly used tool to provide appropriate information about the injuries.

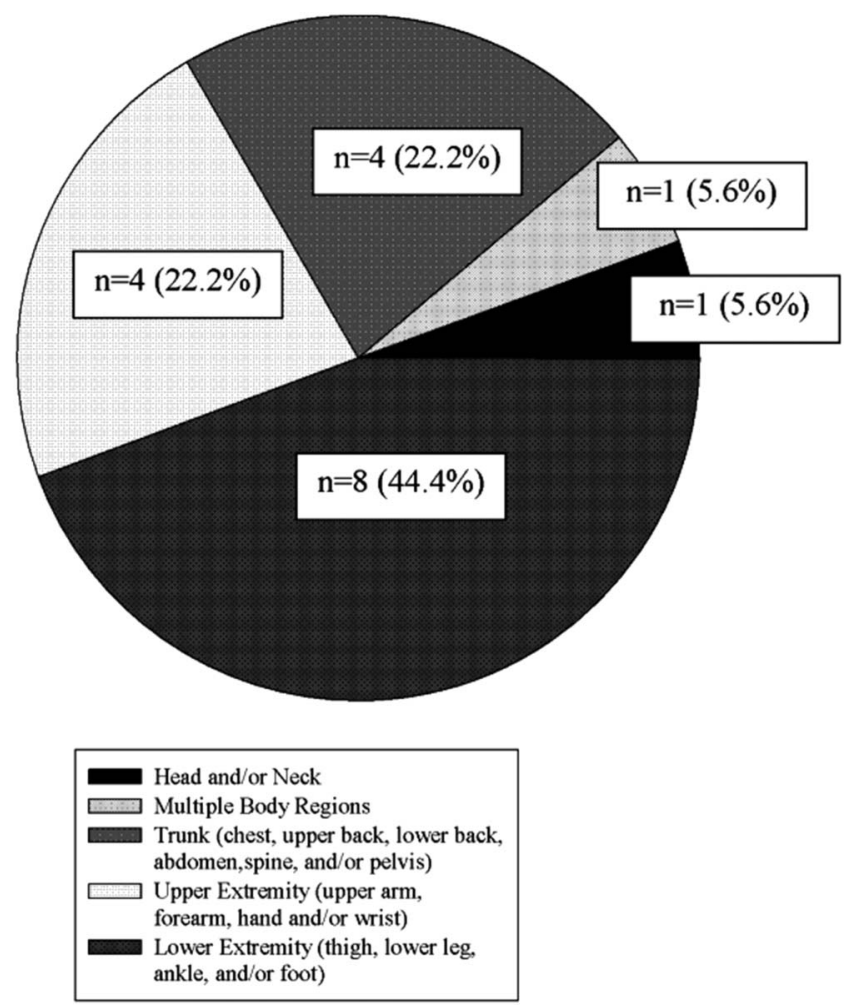

Figure 1 Distribution of body part injured.
The present study is the first to describe exercise-related injuries in an older adult population attending an older adult fitness facility using a newly developed questionnaire. We observed an injury rate of $16 \%$ in community dwelling older adults attending a community-based older adult exercise centre. Epidemiological studies across large age ranges report varying rates of self-reported injuries. The Aerobic Center Longitudinal Study describing musculoskeletal injuries among adults aged 20-85 year reported

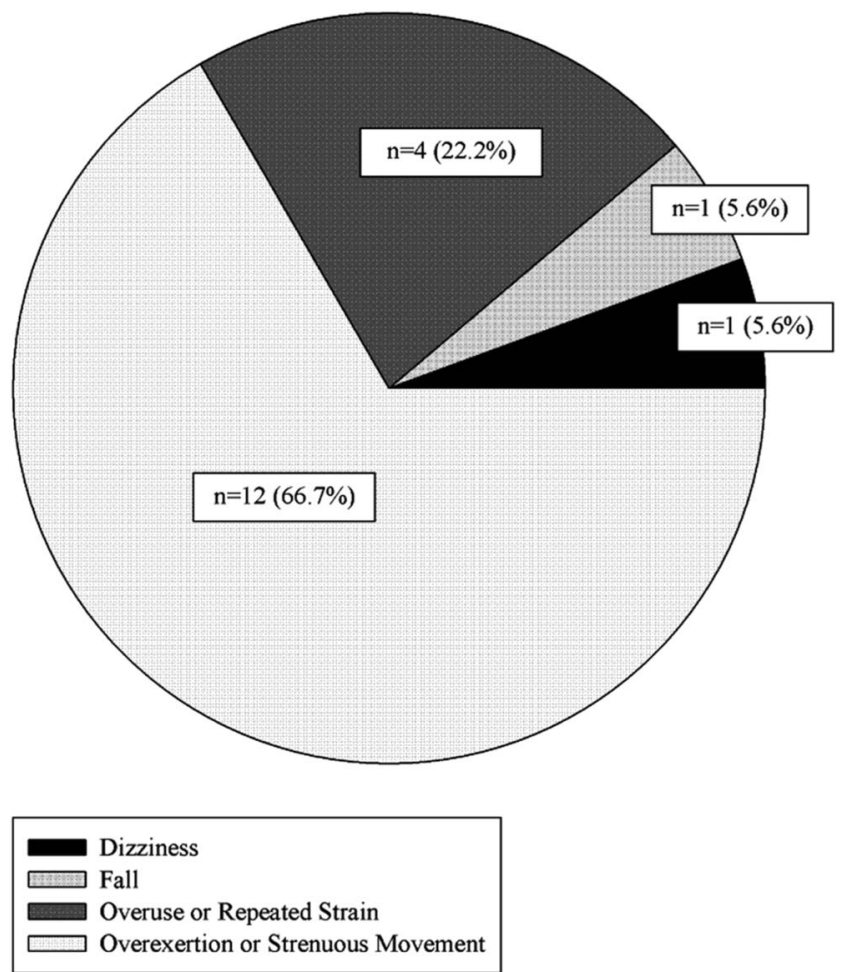

Figure 2 Cause of injury. 


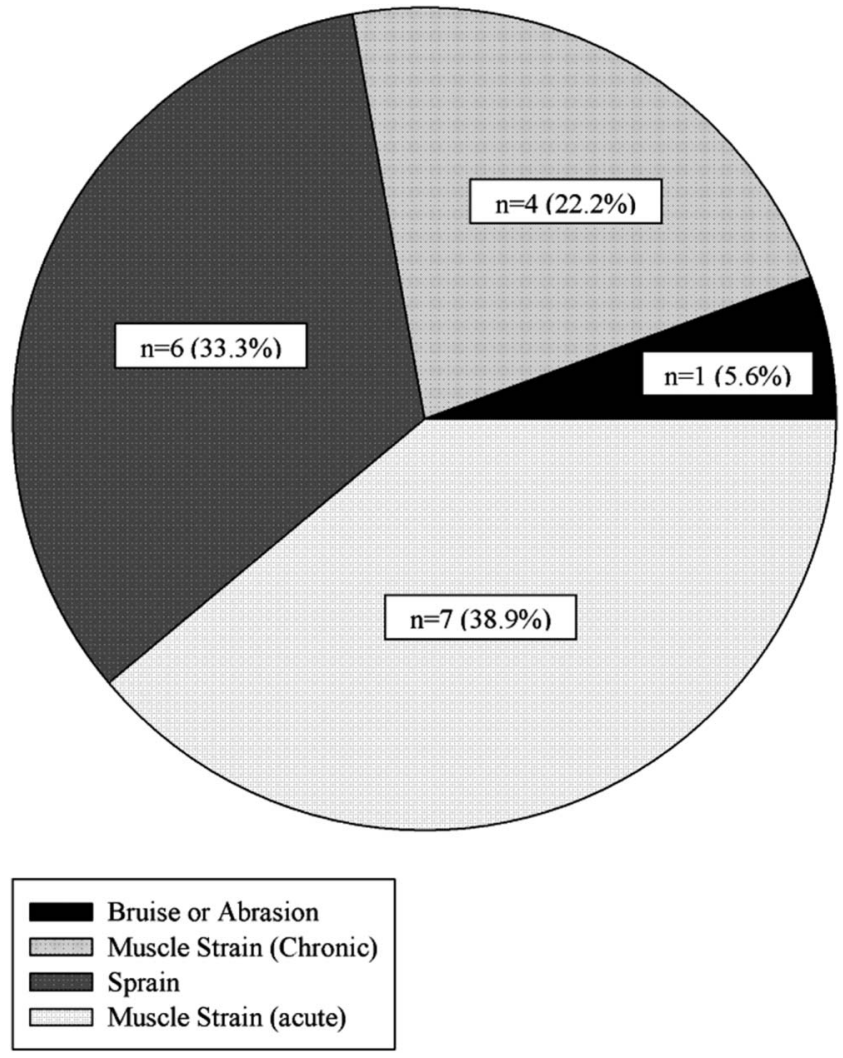

Figure 3 Type of injury.

incidence rates of activity-related injuries to be $21 \%$ in men and 20\% in women. ${ }^{13}$ The 1994 Injury Control and Risk Survey ${ }^{14}$ of adults aged 18 and older reported smaller rates $(0.9-2.4 \%)$ of injury from participation in moderately intense activities. The first national health survey from Germany reported a sport injury rate of $3.1 \%$ for adults aged 18-79 years. Often, large epidemiological studies do not report injury rates for age subgroup or the age groups of older adults are very small. While the literature does not provide a comparison for older adults attending group fitness programmes, randomised control trials of exercise interventions in older adults which document the incidence of injury, report rates ranging from $14 \%$ to $56 \% .^{15-18}$

The present study would indicate that older adults who participate in group fitness exercise classes are not at an increased risk for injury compared with the general population. While one might have expected that older adults attending supervised and specialised fitness classes would have a lower rate of injuries, incidence of injury is related to exposure in terms of time spent participating in activities for which there is an increased risk of injury occurrence (eg, exercise). Studies of highly active older adults versus younger counterparts do not indicate that the rates are higher in the older age groups, ${ }^{19-23}$ and perhaps most importantly, Carlson et $a l^{24}$ have provided evidence that adults $(65+)$ who are active at any level, have a lower incidence of non-sport or no-leisure-time injury than those who are not

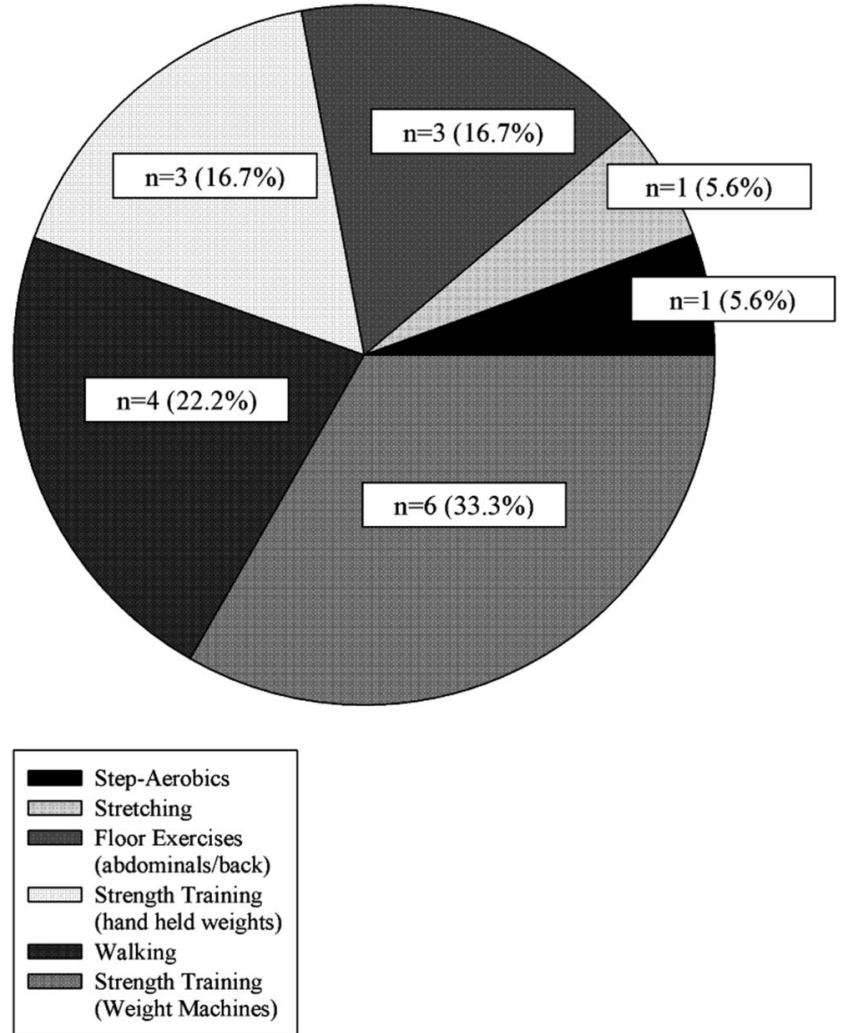

Figure 4 Type of exercise.

(OR 0.41 vs OR 0.61). As such, it appears that fears of increased susceptibility to injuries in the older adult population are unfounded as per the literature available and the benefits of exercise participation outweigh the risk of injury. ${ }^{25}$

In the present study, the men had twice as many injuries as the females, with the main difference being the increased number of injuries occurring as a result of strength training for the men. Larger epidemiological studies across larger age ranges do not show an increased injury between sexes. ${ }^{13}$ A study of injuries during one repetition maximum testing in older men and women resulted in 2 injuries of 83 (one man, one women). ${ }^{26}$ While another reported a $19.3 \%$ injury rate during one repetition maximum testing and $8.7 \%$ during a subsequent strength training intervention (no sex differences were reported). The differences observed between sexes in the present study may be due to the increased effort and/or intensity of men in strength training activities versus women who may prefer lighter intensity weight training loads. Combining injuries as a result of strength training involving both weight machines and free weights, strength training accounted for 9 of the 18 injuries reported. In a retrospective study of weight lifting injuries present to USA emergency departments, it was reported the injury rates in older men accounted for the largest increases in injury rates across the study time. ${ }^{27}$ In addition, the study reported that individuals over the age of 65 years were at slightly 
higher risk of experiencing injuries in the home compared with younger individuals. Strength and power training is important for the maintenance of functional capacity in older adults and as the older adult population becomes more accepting of these activities, further research will be required to document strength training injuries in older adults and to establish safe practice/ supervision guidelines for these activities.

The second leading cause of injury in the present study was walking accounting for 4 of the 18 injuries documented. A 24-week walking intervention of women with a mean age of 60 years yielded an injury rate of $56 \%(\mathrm{n}=28) .{ }^{17}$ The prevalence of walking injury was $1.4 \%$ in a population-based study. ${ }^{14}$ In a large study of regular walkers, Colbert $e t a l^{22}$ reported an injury rate of $18 \%$ for older men and women and suggested that greater amounts of walking do not increase the risk of injury and that the low risk of musculoskeletal injury suggests that waking can be safely recommended as a way to improve health and fitness.

Seasonal differences in injury rates were identified in this study. The present study showed a trend regarding injury rates depending on month of the year, indicating that there were increased injuries during the month of September, October, January and February. This observation is not surprising, as many of the fitness classes show a decline in participation over the summer months and many individuals restart their exercise programmes in September or October. In addition, attendance rates decline in the month of December, particularly in the last 2 weeks of the month. As such, many participants restart their exercise programme in January/February and it is also a time when many people begin an exercise programme. As such, the present trends would indicate that older adults and older adult fitness instructors need to be aware of novice exercisers or those returning to exercise classes after a break from physical activity.

Limitations of the present study include the relatively small sample size that could provide an incidence rate for injuries that would have resulted in greater power. In addition, the present sample represents an independent older adult population attending supervised exercise sessions. Future studies should include a more thorough inclusion of predictor variables for injuries including previous injuries.

\section{CONCLUSIONS}

The described questionnaire assessing the 12-month recall in older adults is a reliable measure of exerciserelated injuries in older adults. Incident report forms filled out by fitness instructors for acute injuries give us an indication of accurate reporting compared to selfreport. It does not appear that older adults participating, in supervised older adult specific multicomponent fitness group classes, are at an increased risk of injury from participation. However, some caution is indicated for strength training activities. A greater knowledge of exercise-related injuries in older adults and in varying settings could lead to prevention strategies that will assist in the continued and safe participation of older adults in physical activity.

\section{Author affiliations}

${ }^{1}$ Department of Kinesiology, University of Western Ontario, London, Canada

${ }^{2}$ Department of Geriatric Medicine, Dalhousie University, Halifax, Canada

${ }^{3}$ Department of Physical Therapy, University of Western Ontario, London, Canada

${ }^{4}$ Department of Clinical Epidemiology and Biostatistics, McMaster University, Hamilton, Canada

Acknowledgements We would like to thank the staff of the Canadian Centre for Activity and Aging Outreach Programs and staff at the McMaster Evidence Based Practice Centre.

Contributors LS, AV and PR designed the study. All authors contributed to analysis and interpretation of data, and contributed to critical revision of the manuscript. LS and OT contributed to acquisition of data, administrative tasks and performed the statistical analysis. LS and OT drafted the manuscript. All author provided final approval of the published version.

Funding Funding for this study was provided by a CIHR ICE Team grant.

Competing interests None.

Patient consent Obtained.

Ethics approval Ethics Board, University of Western Ontario.

Provenance and peer review Not commissioned; externally peer reviewed.

Data sharing statement There are no unpublished data from the present study.

\section{REFERENCES}

1. National Center for Injury Prevention and Control. $C D C$ acute injury care research agenda: guiding research for the future. Atlanta, GA: Centers for Disease Control and Prevention, 2005.

2. Working group for the National Scientific Advisory Committee. Listening for direction on Injury: Identifying priorities for research and capacity development in injury. 2004. Submitted to the Canadian Institutes of Health Research.

3. Kallinen M, Markku A. Aging, physical-activity and sports injuriesan overview of common sports injuries in the elderly. Sports Med 1995;20:41-52.

4. Mummery WK, Spence JC, Vincenten JA, et al. A descriptive epidemiology of sport and recreation injuries in a population based sample: results from the Alberta Sport and Recreation Injury Survey (ASRIS). Can J Public Health 1998;89:53-6.

5. Hootman JM, Macera CA, Ainsworth BE, et al. Epidemiology of musculoskeletal injuries among sedentary and physically active adults. Medi Sci Sports Exer 2003;35:183.

6. Parkkari J, Kannus $P$, Natri $A$, et al. Active living and injury risk. Int $J$ Sports Med 2004;25:209-16.

7. Kallinen M, Markku A. Aging, physical-activity and sports injuriesan overview of common sports injuries in the elderly. Sports Med 1995;20:41-52.

8. Mazzeo RS, Tanaka H. Exercise prescription for the elderly-current recommendations. Sports Med 2001;31:809-18.

9. Chen AL, Mears SC, Hawkins RJ. Orthopaedic care of the aging athlete. J Am Acad Orthop Sur 2005;13:407-16.

10. Broderick CR, Winter GJ, Allan RM. 7. Sport for special groups. Med $J$ Australia 2006:184:297-302.

11. ICECI Coordination and Maintenance Group. International classification of external causes of injuries (ICECI). Adelaide: Consumer Safety Institute, Amsterdam and AlHW National Injury Surveillance Unit, version 1.2, 2004.

12. Norman GR, Streiner DL. Health measurement scales: a practical guide to their development and use. 3rd edn. Oxford: Oxford University Press, 2005.

13. Hootman JM, Macera CA, Ainsworth BE, et al. Epidemiology of musculoskeletal injuries among sedentary and physically active adults. Med Sci Sports Exerc 2002;34:838-44. 
14. Powell KE, Heath GW, Kresnow MJ, et al. Injury rates from walking, gardening, weightlifting, outdoor bicycling, and aerobics. Med Sci Sports Exerc 1998;30:1246-9.

15. Carroll JF, Pollock ML, Graves JE, et al. Incidence of injury during moderate- and high-intensity walking training in the elderly. J Gerontol 1992;47:M61-6.

16. Coleman EA, Buchner DM, Cress ME, et al. The relationship of joint symptoms with exercise performance in older adults. JAGS 1996:44:14-21.

17. Ready AE, Bergeron G, Boreskie SL, et al. Incidence and determinants of injuries sustained by older women during a walking program. JAPA 1999;7:91-104.

18. Pollock ML, Carroll JF, Graves JE, et al. Injuries and adherence to walk/jog and resistance training programs in the elderly. Med Sci Sports Exerc 1991;23:1194-200.

19. Matheson GO, Macintyre JG, Taunton JE, et al. Musculoskeletal injuries associated with physical activity in older adults. Med Sci Sports Exerc 1989;21:379-85.

20. Kujala UM, Nylund T, Taimela S. Acute injuries in orienteerers. Int $J$ Sports Med 1995;16:122-5.
21. Kannus $\mathrm{P}$, Niittymaki $\mathrm{S}$, Jarvinen $\mathrm{M}$, et al. Sports injuries in elderly athletes: a three-year prospective, controlled study. Age Ageing 1989;18:263-70.

22. Colbert LH, Hootman JM, Macera CA. Physical activity-related injuries in walkers and runners in the Aerobics Center Longitudinal Study. Clin J Sport Med 2000;10:259-63.

23. Hootman JM, Macera CA, Ainsworth BE, et al. Predictors of lower extremity injury among recreationally active adults. Clin J Sport Med 2002;12:99-106.

24. Carlson SA, Hootman JM, Powell KE, et al. Self-reported injury and physical activity levels: United States 2000 to 2002. Ann Epidemiol 2006;16:712-19.

25. Farahmand B, Broman G, deFaire U, et al. Golf: a game of life and death-reduced mortality in Swedish golf players. Scan J Med Sci Sports 2009;19:419-24.

26. Shaw CE, McCully KK, Posner JD. Injuries during the one repetition maximum assessment in the elderly. J Cardiopul Rehabil 1995;15:283-7.

27. Jones CS, Christensen $C$, Young M. Weight training injury trends: a 20-year survey. Physician Sportsmed 2000;28:1-9. 